\title{
Unilateral Oculomotor Nerve Enhancement in Diabetic Oculomotor Nerve Palsy: A Retrospective Study
}

Juan Zhao

Beijing Tongren Hospital

Yong Li

Beijing Tongren Hospital

Qing-Lin Chang

Beijing Tongren Hospital

Jia-Wei Wang

Beijing Tongren Hospital

Hou-Liang Sun ( $\square$ autumnshl@163.com )

Beijing Tongren Hospital

Research article

Keywords: Oculomotor nerve palsy, Diabetes, Diabetics, Imaging, MR, Cavernous sinus

Posted Date: July 30th, 2020

DOI: https://doi.org/10.21203/rs.3.rs-45696/v1

License: (c) (1) This work is licensed under a Creative Commons Attribution 4.0 International License. Read Full License 


\section{Abstract}

Background No previous studies have explored the imaging features of oculomotor nerve palsy (ONP) in diabetic patients. In our clinical practice, isolated ONP with diabetes is partly treated with glucocorticosteroids because nerve enhancement is habitually interpreted as inflammation. Our study thus aims to summarize the imaging findings of isolated ONP with diabetes.

Methods Our study included 59 patients with a clinical diagnosis of diabetic ONP. Patients were recruited from our department between January 2015 and December 2019. Orbital MRI was retrospectively analyzed for each patient, and follow-up imaging was obtained for 3 patients.

Results Thickening and enhancement of the ipsilateral oculomotor nerve were detected in $38(64.41 \%)$ patients, indicating simultaneous involvement of the cavernous segment and inferior division of the intraorbital segment. After clinically complete recovery, repeated MRI in 3 patients revealed a slightly reduced degree of enhancement of the oculomotor nerve. No differences were detected in the sex ratio $(p=0.976)$, median onset age $(p=0.563)$, median duration of diabetes $(p=0.697)$, plasma glycosylated hemoglobin (HbAlc) level $(p=0.278)$ or interval from disease onset to MRI between patients with and without enhancement of the oculomotor nerve.

Conclusions Thickening and enhancement of the unilateral oculomotor nerve can be detected in patients with diabetic ONP and indicates the main involvement of the cavernous segment and the inferior division of the intraorbital segment, which may be helpful for differentiating this condition from other etiologies in isolated ONP.

\section{Introduction}

Isolated oculomotor nerve palsy (ONP) is generally thought to result from microvascular ischemia to the nerve and nonmicrovascular conditions including aneurysm and neoplasm compression, inflammation, infection and trauma (1). Microvascular ischemia is regarded as the most common cause (2), and the incidence of cranial nerve palsies among affected patients is 10 -fold higher in those with diabetes than in the nondiabetic population (3). In addition, differences in the incidence rates of other causes of cranial nerve palsies have been reported in diabetic patients $(4,5)$. Thus, the occurrence of isolated ONP in diabetics should be prudently distinguished from occurrences with other etiologies.

With the increasing use of magnetic resonance imaging (MRI), some of the specific causes of isolated ONP have gradually been noted to present corresponding imaging features. However, few studies have presented imaging data obtained in diabetic ONP. Alexander S. Mark et al did not observe oculomotor nerve enhancement in three patients with diabetic $\operatorname{ONP}(6,7)$, but further studies have not been performed. In clinical practice, we noticed that some patients with a clinical diagnosis of diabetic ONP presented with thickening and enhancement of the ipsilateral oculomotor nerve on MRI and that these patients were usually treated with glucocorticosteroids because the nerve enhancement was interpreted as inflammation. Hence, our study explores the orbital imaging findings in diabetic ONP to determine whether abnormalities in these patients can offer some clues to differentiating this etiology from others. 


\section{Methods}

Our investigation enrolled 59 Chinese Han patients with a clinical diagnosis of diabetic ONP who were admitted to our department between January 2015 and December 2019.

The inclusion criteria were as follows: 1) acute onset of ophthalmoplegia with ptosis resulting from unilateral ONP; 2) no pupillary involvement; 3 ) a history of diabetes or pathoglycemia or newly diagnosed diabetes with or without cardio-cerebrovascular disorders; 4) no history of concurrent infection, migraine, head trauma, neurosurgery, malignancy, Sjögren's syndrome, systemic lupus erythematosus, rheumatoid arthritis, vasculitis, cranial herpes zoster, or immunocompromised status; and 5) exclusion of intracranial aneurysm based on head magnetic resonance angiography or computed tomography angiography.

Medical records were reviewed to obtain data including sex, onset age, the duration of diabetes, laboratory data and treatment strategies. Orbital MRI was performed for each patient at the first visit using a standard head coil on a 3.0-T GE Signa HDxt MR scanner (GE Healthcare, Milwaukee, Wisconsin, USA). All patients underwent imaging procedures, including precontrast T1-weighted and T2-weighted sequences in the axial plane, immediate postcontrast T1-weighted images in the axial and coronal planes, and short-tau inversion recovery (STIR) sequences in the coronal planes (3-mm thick, 0.5-mm interslice gap). The parameters used in our study were as follows: spin echo (SE) T1 (TR 400 ms, TE 10 ms), T2 (TR 3000 ms, TE $120 \mathrm{~ms}$ ) and STIR (TR 606 ms, TE $7.2 \mathrm{~ms}$ ) sequences. Gadolinium diethylenetriamine pentaacetic acid (Gd-DTPA) injection was administered intravenously at a dose of $0.1 \mathrm{mmol} / \mathrm{kg}$ in all patients.

As mentioned by Alexander S. Mark (6), thickening of the oculomotor nerve was clearly identified when it appeared larger on one side than on the contralateral side on postcontrast coronal images. Enhancement of the oculomotor nerve was reported when its intensity increased after Gd-DTPA administration.

The coronal STIR sequences were utilized to assess the size of the extraocular muscles (EOMs) including the medial rectus (MR), lateral rectus (LR), inferior rectus (IR), superior rectus (SR), levator palpebrae superioris (LPS) and superior oblique (SO) muscles. The inferior oblique muscle was not evaluated in this study because only a few slices of this muscle were included in the coronal plane. The SR and LPS were regarded together as the superior muscle group (SMG) because these structures were difficult to delineate from each other. Atrophy of the EOMs was recorded when they appeared thinner on one side than on the contralateral side.

The images were interpreted and evaluated retrospectively by two experienced neuroradiologists and three neurologists in our hospital.

Statistical analyses were performed using IBM Statistical Package for Social Sciences (SPSS) version 19.0 software (IBM, New York, USA). Descriptive statistics are expressed as the mean \pm standard deviation (SD) for continuous data, including onset age, the duration of diabetes, and fasting blood sugar and HbAlc levels, whereas a number and percentage are presented for categorical data, such as the sex ratio and the incidence of pain. For comparisons between the enhancement and nonenhancement groups, the MannWhitney $U$ test was utilized to analyze differences in the continuous data listed above, and the chi-squared 
test was used to analyze categorical variables and the ratio of nerve enhancement when patients were further divided into different subgroups based on the timing of imaging. A two-tailed $p$-value less than 0.05 was considered significant for all .

\section{Results}

\section{Clinical Data}

The basic clinical data of the 59 included patients are summarized in Table 1. The median onset age was 65 (range, 29-85) years. Complaints of pain were present in 37 patients. Pain was alleviated in five patients (cases 25, 33, 36, 43, and 49) with the use of ibuprofen or carbamazepine and was thus graded as moderate, and pain was mild in the remaining patients. Restriction of elevation, depression and adduction was observed, and the contralateral eye showed normal movements in all directions in all patients. No evidence of simultaneous involvement of other cranial nerves or pyramidal, extrapyramidal and cerebellar signs was found. 
Table 1

Basic clinical data for our patients

\begin{tabular}{|c|c|c|c|c|c|c|c|c|}
\hline $\begin{array}{l}\text { Patient } \\
\text { Number }\end{array}$ & Sex & $\begin{array}{l}\text { Onset- } \\
\text { age } \\
\text { (Years) }\end{array}$ & $\begin{array}{l}\text { Duration } \\
\text { of DM } \\
\text { (Years) }\end{array}$ & $\begin{array}{l}\text { HbAlc, \% } \\
(\mathrm{mmol} / \mathrm{mol})\end{array}$ & Pain & ONP & $\begin{array}{l}\text { Time } \\
\text { interval } \\
\text { from } \\
\text { disease } \\
\text { onset } \\
\text { to MRI }\end{array}$ & Glucocorticosteroids \\
\hline 1 & $\mathrm{~F}$ & 79 & 30 & $9.3(78)$ & $\sqrt{ }$ & L & $\begin{array}{l}\text { over } 1 \\
\text { month }\end{array}$ & No \\
\hline 2 & $\mathrm{~F}$ & 29 & 0 & $6.9(52)$ & $\sqrt{ }$ & $\mathrm{R}$ & $\begin{array}{l}\text { over } 1 \\
\text { month }\end{array}$ & Yes (before) \\
\hline 3 & M & 75 & 0.5 & $6.2(44)$ & $\sqrt{ }$ & $\mathrm{R}$ & $\begin{array}{l}1 \\
\text { month }\end{array}$ & No \\
\hline 4 & $M$ & 71 & 6 & $6.4(46)$ & $x$ & $\mathrm{R}$ & $\begin{array}{l}12 \\
\text { days } \\
\text { and } 3.5 \\
\text { months }\end{array}$ & Yes (after) \\
\hline 5 & $\mathrm{~F}$ & 56 & 10 & $10.1(87)$ & $x$ & L & $\begin{array}{l}3 \\
\text { weeks }\end{array}$ & No \\
\hline 6 & $\mathrm{~F}$ & 59 & 2 & $6.8(51)$ & $x$ & L & $\begin{array}{l}6 \\
\text { weeks }\end{array}$ & Yes(after) \\
\hline 7 & M & 67 & 2 & $5.7(39)$ & $x$ & L & $\begin{array}{l}10 \\
\text { days }\end{array}$ & No \\
\hline 8 & M & 74 & 10 & $7.9(63)$ & $\sqrt{ }$ & L & $\begin{array}{l}\text { over } 1 \\
\text { month }\end{array}$ & No \\
\hline 9 & $\mathrm{~F}$ & 70 & 13 & $8(64)$ & $x$ & $\mathrm{R}$ & $\begin{array}{l}10 \\
\text { days }\end{array}$ & No \\
\hline 10 & M & 43 & 15 & $9.1(76)$ & $\sqrt{ }$ & $\mathrm{R}$ & $\begin{array}{l}10 \\
\text { days }\end{array}$ & No \\
\hline 11 & M & 57 & 20 & $8.3(67)$ & $\sqrt{ }$ & L & $\begin{array}{l}22 \\
\text { days }\end{array}$ & No \\
\hline 12 & $M$ & 42 & 2 & 7.3(56) & $\sqrt{ }$ & L & $\begin{array}{l}4 \\
\text { weeks }\end{array}$ & Yes(after) \\
\hline \multirow[t]{2}{*}{13} & $M$ & 41 & 7 & $8.3(67)$ & $x$ & $\mathrm{R}$ & $\begin{array}{l}1 \\
\text { month } \\
\text { and }\end{array}$ & No \\
\hline & & & & & & & $\begin{array}{l}3.5 \\
\text { months }\end{array}$ & \\
\hline 14 & $M$ & 67 & 30 & $10.4(90)$ & $\sqrt{ }$ & $\mathrm{R}$ & $\begin{array}{l}23 \\
\text { days }\end{array}$ & No \\
\hline
\end{tabular}

$R$, the Right side; $L$, the Left side; $\sqrt{ }$, existence of pain; $\times$, nonexistence of pain; before, administration of glucocorticosteroids before orbital MRI; after, administration of glucocorticosteroids after orbital MRI. 


\begin{tabular}{|c|c|c|c|c|c|c|c|c|}
\hline $\begin{array}{l}\text { Patient } \\
\text { Number }\end{array}$ & Sex & $\begin{array}{l}\text { Onset- } \\
\text { age } \\
\text { (Years) }\end{array}$ & $\begin{array}{l}\text { Duration } \\
\text { of DM } \\
\text { (Years) }\end{array}$ & $\begin{array}{l}\text { HbAlc, \% } \\
(\mathrm{mmol} / \mathrm{mol})\end{array}$ & Pain & ONP & $\begin{array}{l}\text { Time } \\
\text { interval } \\
\text { from } \\
\text { disease } \\
\text { onset } \\
\text { to MRI }\end{array}$ & Glucocorticosteroids \\
\hline 15 & $M$ & 85 & 0 & $6.5(48)$ & $x$ & L & $\begin{array}{l}10 \\
\text { days }\end{array}$ & No \\
\hline 16 & M & 55 & 10 & $8.7(72)$ & $x$ & $\mathrm{R}$ & $\begin{array}{l}40 \\
\text { days }\end{array}$ & No \\
\hline 17 & $F$ & 62 & 20 & $8.5(69)$ & $x$ & $\mathrm{R}$ & $\begin{array}{l}\text { about } 2 \\
\text { weeks } \\
\text { and } 9 \\
\text { months }\end{array}$ & No \\
\hline 18 & M & 67 & 15 & $8.6(70)$ & $\sqrt{ }$ & L & $\begin{array}{l}19 \\
\text { days }\end{array}$ & No \\
\hline 19 & $M$ & 44 & 10 & $7.9(63)$ & $x$ & $\mathrm{R}$ & $\begin{array}{l}29 \\
\text { days }\end{array}$ & Yes (before) \\
\hline 20 & M & 71 & 30 & 7.3(56) & $\sqrt{ }$ & $\mathrm{R}$ & $\begin{array}{l}\text { over } 1 \\
\text { month }\end{array}$ & No \\
\hline 21 & $\mathrm{~F}$ & 66 & 20 & $7.5(58)$ & $x$ & $\mathrm{R}$ & $\begin{array}{l}27 \\
\text { days }\end{array}$ & No \\
\hline 22 & $M$ & 65 & 10 & $7.8(62)$ & $x$ & L & $\begin{array}{l}53 \\
\text { days }\end{array}$ & No \\
\hline 23 & $\mathrm{~F}$ & 77 & 0 & $6(42)$ & $x$ & L & $\begin{array}{l}19 \\
\text { days }\end{array}$ & No \\
\hline 24 & M & 64 & 10 & $6.9(52)$ & $\sqrt{ }$ & $\mathrm{R}$ & $\begin{array}{l}12 \\
\text { days }\end{array}$ & No \\
\hline 25 & $\mathrm{~F}$ & 53 & 0.25 & $6.1(43)$ & $\sqrt{ }$ & $\mathrm{R}$ & $\begin{array}{l}2 \\
\text { weeks }\end{array}$ & Yes(after) \\
\hline 26 & $\mathrm{~F}$ & 82 & 0 & $8.5(69)$ & $x$ & L & $\begin{array}{l}2 \\
\text { weeks }\end{array}$ & No \\
\hline 27 & M & 62 & 10 & $9.9(85)$ & $\sqrt{ }$ & L & $\begin{array}{l}2 \\
\text { weeks }\end{array}$ & No \\
\hline 28 & M & 45 & 5 & $9.2(77)$ & $\sqrt{ }$ & $\mathrm{R}$ & $\begin{array}{l}34 \\
\text { days }\end{array}$ & Yes (before) \\
\hline 29 & M & 77 & 25 & $8.7(72)$ & $\sqrt{ }$ & $\mathrm{L}$ & $\begin{array}{l}3 \\
\text { weeks }\end{array}$ & No \\
\hline 30 & M & 62 & 3 & $5.8(40)$ & $x$ & L & $\begin{array}{l}18 \\
\text { days }\end{array}$ & No \\
\hline
\end{tabular}

$R$, the Right side; $L$, the Left side; $\sqrt{ }$, existence of pain; $x$, nonexistence of pain; before, administration of glucocorticosteroids before orbital MRI; after, administration of glucocorticosteroids after orbital MRI. 


\begin{tabular}{|c|c|c|c|c|c|c|c|c|}
\hline $\begin{array}{l}\text { Patient } \\
\text { Number }\end{array}$ & Sex & $\begin{array}{l}\text { Onset- } \\
\text { age } \\
\text { (Years) }\end{array}$ & $\begin{array}{l}\text { Duration } \\
\text { of DM } \\
\text { (Years) }\end{array}$ & $\begin{array}{l}\text { HbAlc, \% } \\
(\mathrm{mmol} / \mathrm{mol})\end{array}$ & Pain & ONP & $\begin{array}{l}\text { Time } \\
\text { interval } \\
\text { from } \\
\text { disease } \\
\text { onset } \\
\text { to MRI }\end{array}$ & Glucocorticosteroids \\
\hline 31 & M & 64 & 20 & $9.3(78)$ & $\sqrt{ }$ & $\mathrm{R}$ & $\begin{array}{l}3 \\
\text { weeks }\end{array}$ & No \\
\hline 32 & $\mathrm{M}$ & 64 & 18 & $7.8(62)$ & $\sqrt{ }$ & L & $\begin{array}{l}2 \\
\text { weeks }\end{array}$ & No \\
\hline 33 & $\mathrm{~F}$ & 73 & 4 & $6.9(52)$ & $\sqrt{ }$ & $\mathrm{L}$ & $\begin{array}{l}10 \\
\text { days }\end{array}$ & No \\
\hline 34 & M & 65 & 10 & 10.7(93) & $\sqrt{ }$ & $\mathrm{L}$ & $\begin{array}{l}10 \\
\text { days }\end{array}$ & No \\
\hline 35 & $M$ & 65 & 1 & $7.5(58)$ & $x$ & L & $\begin{array}{l}23 \\
\text { days }\end{array}$ & No \\
\hline 36 & $M$ & 82 & 20 & $6.7(50)$ & $\sqrt{ }$ & $\mathrm{R}$ & $\begin{array}{l}3 \\
\text { weeks }\end{array}$ & No \\
\hline 37 & $\mathrm{M}$ & 42 & 7 & $9.2(77)$ & $x$ & $\mathrm{R}$ & $\begin{array}{l}11 \\
\text { days }\end{array}$ & No \\
\hline 38 & M & 68 & 14 & $7.3(56)$ & $x$ & $\mathrm{R}$ & $\begin{array}{l}2 \\
\text { weeks }\end{array}$ & No \\
\hline 39 & M & 60 & 5 & $6.6(49)$ & $\sqrt{ }$ & $\mathrm{R}$ & 6 days & No \\
\hline 40 & $\mathrm{~F}$ & 55 & 13 & 10.1(87) & $\sqrt{ }$ & L & $\begin{array}{l}25 \\
\text { days }\end{array}$ & Yes (before) \\
\hline 41 & $\mathrm{~F}$ & 70 & 10 & $6.5(48)$ & $\sqrt{ }$ & $\mathrm{R}$ & 9 days & No \\
\hline 42 & M & 65 & 4 & $9(75)$ & $x$ & $\mathrm{R}$ & 6 days & No \\
\hline 43 & M & 84 & 2 & $5.9(41)$ & $\sqrt{ }$ & $\mathrm{R}$ & 6 days & Yes(after) \\
\hline 44 & $M$ & 34 & 14 & $10.4(90)$ & $\sqrt{ }$ & $\mathrm{R}$ & $\begin{array}{l}10 \\
\text { days }\end{array}$ & No \\
\hline 45 & $M$ & 80 & 6 & $7.5(58)$ & $\sqrt{ }$ & L & $\begin{array}{l}18 \\
\text { days }\end{array}$ & No \\
\hline 46 & $\mathrm{~F}$ & 82 & 30 & $9(75)$ & $\sqrt{ }$ & $\mathrm{R}$ & $\begin{array}{l}9 \\
\text { weeks }\end{array}$ & No \\
\hline 47 & $\mathrm{M}$ & 65 & 21 & $7.1(54)$ & $\sqrt{ }$ & L & $\begin{array}{l}7 \\
\text { weeks }\end{array}$ & No \\
\hline 48 & $\mathrm{M}$ & 61 & 0 & $6.4(46)$ & $\sqrt{ }$ & L & $\begin{array}{l}11 \\
\text { days }\end{array}$ & No \\
\hline
\end{tabular}

$R$, the Right side; $L$, the Left side; $\sqrt{ }$, existence of pain; $x$, nonexistence of pain; before, administration of glucocorticosteroids before orbital MRI; after, administration of glucocorticosteroids after orbital MRI. 


\begin{tabular}{|c|c|c|c|c|c|c|c|c|}
\hline $\begin{array}{l}\text { Patient } \\
\text { Number }\end{array}$ & Sex & $\begin{array}{l}\text { Onset- } \\
\text { age } \\
\text { (Years) }\end{array}$ & $\begin{array}{l}\text { Duration } \\
\text { of DM } \\
\text { (Years) }\end{array}$ & $\begin{array}{l}\text { HbAlc, \% } \\
(\mathrm{mmol} / \mathrm{mol})\end{array}$ & Pain & ONP & $\begin{array}{l}\text { Time } \\
\text { interval } \\
\text { from } \\
\text { disease } \\
\text { onset } \\
\text { to MRI }\end{array}$ & Glucocorticosteroids \\
\hline 49 & $F$ & 66 & 10 & $8.3(67)$ & $\sqrt{ }$ & $\mathrm{R}$ & $\begin{array}{l}17 \\
\text { days }\end{array}$ & No \\
\hline 50 & M & 71 & 0.08 & $6.5(48)$ & $\sqrt{ }$ & L & $\begin{array}{l}5 \\
\text { weeks }\end{array}$ & No \\
\hline 51 & $\mathrm{~F}$ & 66 & 2 & $7.6(60)$ & $\sqrt{ }$ & $\mathrm{R}$ & $\begin{array}{l}2 \\
\text { weeks }\end{array}$ & No \\
\hline 52 & M & 55 & 15 & $8.1(65)$ & $\sqrt{ }$ & $\mathrm{R}$ & $\begin{array}{l}4 \\
\text { weeks }\end{array}$ & No \\
\hline 53 & $M$ & 76 & 5 & 7.2(55) & $\sqrt{ }$ & $\mathrm{R}$ & 1 week & No \\
\hline 54 & M & 62 & 30 & $6.9(52)$ & $\sqrt{ }$ & L & $\begin{array}{l}2 \\
\text { weeks }\end{array}$ & Yes(after) \\
\hline 55 & $M$ & 56 & 15 & 7.4(57) & $x$ & $\mathrm{R}$ & 6 days & No \\
\hline 56 & $\mathrm{~F}$ & 63 & 3 & $8(64)$ & $\sqrt{ }$ & $\mathrm{R}$ & 8 days & No \\
\hline 57 & $M$ & 57 & 10 & $7(53)$ & $x$ & $\mathrm{R}$ & $\begin{array}{l}25 \\
\text { days }\end{array}$ & Yes(after) \\
\hline 58 & M & 78 & 4 & $6.5(48)$ & $\sqrt{ }$ & $\mathrm{R}$ & $\begin{array}{l}24 \\
\text { days }\end{array}$ & No \\
\hline 59 & M & 79 & 2 & $6.4(46)$ & $x$ & L & $\begin{array}{l}3 \\
\text { weeks }\end{array}$ & No \\
\hline
\end{tabular}

Lumbar puncture was performed in four patients (cases 6, 12, 23, and 29) and showed a normal opening pressure, cell count, glucose level, and protein levels and negative results for gram-stained smears, modified acid-fast staining, ink staining, oligoclonal IgG, myelin basic protein, intrathecal IgG synthesis, and IgM antibody titer against herpes simplex virus, cytomegalovirus, toxoplasma, EB virus and rubella virus.

All patients were prescribed aspirin, vitamin B12, and drugs to ameliorate microcirculation and maintain optimal glycemic control as well drugs to minimize the other stronger risk factors for ischemia, including hypertension and hyperlipidemia. Eleven patients were simultaneously treated with glucocorticosteroids before or after imaging.

A telephone follow-up was performed in all patients, although four (cases $2,9,15$, and 16) were lost to follow-up. Among the remaining patients, three to six months was required to achieve complete restoration except for case 5 in whom the symptoms were alleviated by $90 \%$ as of a follow-up performed approximately four months after illness onset. 


\section{Imaging Findings}

All patients underwent an initial examination with orbital MRI within 53 days of the occurrence of ophthalmoplegia or ptosis (Table 1). Because of initially inconclusive diagnoses, a therapeutic trial of glucocorticosteroids was prescribed to 4 patients before imaging and another 7 patients after imaging mainly based on nerve enhancement or reports of moderate pain.

Thickening and enhancement of the ipsilateral oculomotor nerve were detected on orbital MRI in cases 1$38(64.41 \%, 38 / 59)$ in whom the cavernous segment and inferior division of the intraorbital segment were simultaneously involved (Fig. 1). Because of the small size of and complicated neighboring structures in the orbit, the superior division of the oculomotor nerve was not consistently identified in all patients. No patients showed abnormal enlargement or mass-like enhancement of the cavernous sinus extending through the superior orbital fissure into the orbital apex. Pituitary abnormalities and meningeal enhancement were not detected in any patients.

Figure 1 Postgadolinium coronal STIR images on MRI in case 2. (a) Thickening and enhancement of the cavernous segment of the right oculomotor nerve. (b) Thickening and enhancement of the inferior division of the intraorbital segment of the right oculomotor nerve.

Thinning of EOMs was simultaneously observed in the 38 patients (Fig. 2a). In eight of these patients (cases 2, 5, 6, 12, 22, 23, 31 and 32), involvement of the unilateral MR and IR was detected. In three cases (cases 3,11 and 28), only the unilateral MR was affected. The unilateral MR, IR and SMG were thinned in the remaining patients. Enhancement of the EOMs and dilatation of the superior ophthalmic vein were not detected in any patient.

Figure 2. Postgadolinium coronal STIR images on MRI in case 17. (a) Thinning of the unilateral MR, IR and SMG was shown on images taken 1.5 months after disease onset. (b) Comparative images taken 8 months later displayed that thinning of the EOMs was partly restored.

Repeated MRI was performed in 3 patients approximately 3.5 months after onset since ophthalmoplegia developed in cases 4 and 13 and 8 months after onset in case 17 in whom a slightly reduced degree of enhancement of the oculomotor nerve was observed. The appearances of the EOMs were also partly restored based on MRI (Fig. 2b).

Based on orbital MRI, these patients were divided into enhancement and nonenhancement groups. The demographic data and clinical presentations of these groups are summarized in Table 2. Regarding the sex ratio, median onset age, median duration of diabetes, and fasting blood sugar and HbAlc levels, no significant differences were found between the groups. The incidence of pain was significantly higher in the nonenhancement group than in the enhancement group ( $80.95 \%$ versus $52.63 \%, p=0.031)$. Significant differences were not detected when these patients were further divided based on the time interval from disease onset to MRI into two subgroups ( $\leq 4$ weeks and $>4$ weeks $)(p=0.671)$ or three subgroups $(\leq 2$ weeks, $2-4$ weeks and $>4$ weeks $)(p=0.913)$. 
Table 2

Demographic data and clinical manifestations of 59 patients with diabetic ONP

\begin{tabular}{|llll|}
\hline & Enhancement Group & Nonenhencement Group & p value \\
\hline $\mathrm{N}(\%)$ & $38(64.41)$ & $21(35.59)$ & \\
\hline $\mathrm{M} / \mathrm{F}$ & $26 / 12$ & $15 / 6$ & 0.976 \\
\hline Onset-age(year) & $62.89 \pm 13.12$ & $65.95 \pm 11.76$ & 0.563 \\
\hline Duration Of Diabetes & $10.78 \pm 9.07$ & $9.58 \pm 8.86$ & 0.697 \\
(year) & & & 0.931 \\
\hline Fasting Blood Sugar (mmol/L) & $7.01 \pm 2.56$ & $6.99 \pm 2.12$ & 0.278 \\
\hline HbAlc(\%) & $7.70 \pm 1.84$ & $7.23 \pm 2.05$ & 0.031 \\
\hline Incidence Of Pain, N(\%) & $20(52.63)$ & $17(80.95)$ & \\
\hline $\begin{array}{l}\text { ONP, oculomotor nerve palsy; Enhancement group, Enhancement of the oculomotor nerve; } \\
\text { Nonenhencement group, nonenhencement of the oculomotor nerve. }\end{array}$ \\
\hline
\end{tabular}

\section{Discussion}

Anatomically, after the fascicular portion of the oculomotor nerve travels ventrally from the nucleus origin in the dorsal midbrain tegmentum, it can be divided into the cisternal, cavernous and intraorbital segments, which branch into superior and inferior branches within the superior orbital fissure $(8,9)$. In total, extra-axial lesions should account for the ONP observed in our study. However, ONP in diabetic patients does not always indicate diabetes-related microvascular ischemic ONP, and further evidence, such as imaging procedures, is indispensable for obtaining an etiological diagnosis.

In our study, the most common imaging findings were thickening and enhancement of the cavernous segment and the inferior division of the intraorbital segment of the ipsilateral oculomotor nerve. Oculomotor nerve enhancement was previously confirmed to be an indication of a variety of underlying etiologies, such as Tolosa-Hunt syndrome (THS), recurrent painful ophthalmoplegic neuropathy and oculomotor nerve tumors $(6,10-13)$, each of which could be eliminated as a differential diagnosis in our patients. However, immediate pain relief was not achieved within 72 hours of treatment with glucocorticosteroids, and no study of THS has reported a case in which the oculomotor nerve is solely thickened and enhanced without enlargement of the cavernous sinus in THS (11). Several patients with recurrent painful ophthalmoplegic neuropathy have also revealed unilateral thickening and enhancement of the oculomotor nerve, but an association between recurrent headache and ONP must be emphasized, with most affected patients having pupillary involvement (14-17). Solid tumors frequently demonstrated nodular enhancement of the cisternal segment, and some show either extension of a mass lesion into the cavernous sinus or increased tissue in the sinus that may extend into the superior orbital fissure; however, spontaneous resolution of both presentations of ONP and imaging abnormalities has never been reported under these circumstances. Isolated unilateral cranial nerve palsy without systemic manifestations is relatively rare in nonsolid tumors, 
and thus far, only Joana Meireles has reported one such patient, a 69-year-old woman in whom the first presentation of Hodgkin's lymphoma was left oculomotor nerve enhancement with no brain parenchymal or meningeal abnormalities or cavernous sinus involvement (18); importantly, pancytopenia emerged three months after ONP in this patient. In addition, pupillary involvement and spontaneous recovery within 6 months are not classical manifestations of lymphoma and should thus be excluded in diabetic ONP patients.

Our study first demonstrates that enhancement of the ipsilateral oculomotor nerve was observed in $64.41 \%$ of the included patients, which may therefore be added as a supportive diagnostic criterion for diabetic ONP with main involvement of the cavernous segment and inferior division of the intraorbital segment. The pain incidence was higher in patients without enhancement of the oculomotor nerve than in those with enhancement, although this difference may have been caused by recall bias and differences in pain tolerance among the patients. Similar to previous reports, more than three months was required for our patients to achieve complete recovery even when treated with glucocorticosteroids in the early stage, which may indicate that glucocorticosteroids use does not shorten the disease course of diabetic ONP. Therefore, oculomotor nerve enhancement should not be habitually interpreted as inflammation and glucocorticosteroids should not be directly administered to these patients. Refraining from glucocorticosteroids in diabetic ONP may reduce the risk of poorer glycemic control, infection and other vascular events.

Thickening and enhancement of the oculomotor nerve have never previously been reported in diabetic ONP. Although scholars have not reached a consensus on immediate neuroimaging for patients up to 50 years of age with isolated ONP (19-21), MRI is routinely performed in our clinic regardless of the onset age to evaluate the entire course of the oculomotor nerve and surrounding structures to avoid missing any rare causative factors, especially in deeply embedded structures, given the intense medical environment in our country.

In our study, the occurrence of nerve enhancement was not always positively correlated with blood sugar control. Other factors such as elevated levels of inflammatory biomarkers may accompany nerve enhancement in a hyperglycemia-independent manner $(22,23)$. These insults can also break down the blood-nerve barrier, an initial key step in the development of diabetic neuropathy (24-26) that allows the leakage and accumulation of contrast material with resultant nerve enhancement as observed in our study. Differences in the kinds and concentrations of these metabolic and inflammatory elements, which were unaffected by the level of blood sugar and the timing of imaging, may be the underlying explanation for the observed nerve enhancement.

In 1970, Asbury AK et al reported an autopsy case of a diabetic ONP patient who had experienced right ONP three years prior to and a second ophthalmoplegia event on the left side just one month prior to death (27). A striking focal demyelinating lesion of the intracavernous portion and enlargement and septation of the left oculomotor nerve by connective tissue bands in the anterior half of the cavernous sinus were found, which may have been the underlying pathologies for the thickening and enhancement of the intracavernous portion of the oculomotor nerve observed in our patients. However, pathological changes in the intraorbital 
segment were not explored. Asbury AK et al also found no evidence of previous damage to axons or myelin sheaths in the right oculomotor nerve. However, the enhancement of the oculomotor nerve observed in our patients did not disappear until follow-up. This discrepancy may be due to the relatively short follow-up period of our study. Partial restoration of the appearance of the EOMs may suggest gradual functional recovery prior to the disappearance of nerve enhancement. The follow-up should be continued to determine whether the appearance of the EOMs will be restored, the time required for this process, and when the nerve enhancement will finally disappear.

Our study has several limitations. First, its retrospective nature did not allow us to evaluate the detailed time of recovery from ONP, and further analyzing differences in recovery times between patients with and without nerve enhancement was difficult. Second, follow-up imaging data were lacking for the vast majority of the patients, and these data should be obtained after complete recovery from ONP to track changes in the trends of oculomotor nerve enhancement and determine whether this kind of enhancement will finally disappear. Third, our study did not enroll patients with ischemic ONP with other atherosclerotic risk factors apart from diabetes; therefore, the incidence of unilateral oculomotor enhancement among all patients with ischemic ONP remains unclear. Extensive investigation is needed to resolve these issues in future studies.

\section{Conclusions}

Our study demonstrates that thickening and enhancement of the unilateral oculomotor nerve were detected on MRI in patients with diabetic ONP, with the main involvement observed in the cavernous segment and inferior division of the intraorbital segment. These findings may be helpful for differentiating diabetic ONP from other etiologies of isolated ONP. Glucocorticosteroids did not seem to shorten the disease course and should be avoided even with enhancement of the oculomotor nerve in diabetic ONP.

\section{List Of Abbreviations}

ONP oculomotor nerve palsy

HbAlc plasma glycosylated hemoglobin

MRI magnetic resonance imaging

STIR short-tau inversion recovery

SE spin echo

Gd-DTPA Gadolinium diethylenetriamine pentaacetic acid

EOMs extraocular muscles

MR medial rectus

LR lateral rectus 
IR inferior rectus

SR superior rectus

LPS levator palpebrae superioris

SO superior oblique muscles

SMG the superior muscle group

SPSS Statistical Package for Social Sciences

SD standard deviation

THS Tolosa-Hunt syndrome

\section{Declarations}

\section{Ethics approval and consent to participate}

This study adhered to the tenets of the Declaration of Helsinki and was approved by the Ethics Committee of Beijing Tongren Hospital, Capital Medical University. Written or oral consent was not obtained from patients because our study was retrospective and exemption from informed consent was applied before its beginning.

\section{Consent for publication}

Written informed consent for use of the image for publication was obtained from the patients. A copy of written consent form is available for review to the Editor of this journal.

\section{Availability of data and materials}

The data that support the findings of this study are available from the corresponding author but restrictions apply to the availability of these data, which were used under license for the current study, and so are not publicly available. Data are however available from the authors upon reasonable request and with permission of our institution.

\section{Competing interests}

The authors declare that they have no competing interests.

\section{Funding}




\section{Authors' contributions}

JZ and HLS designed the work, YL, QLC and JWW participated in the data acquisition and contributed to the analysis of the data. JZ interpreted the data and have drafted the paper. HLS substantively revised the manuscript. All authors have read and approved the final manuscript.

\section{Acknowledgements}

Not applicable.

\section{Footnotes}

\section{Publisher's Note}

Springer Nature remains neutral with regard to jurisdictional claims in published maps and institutional affiliations.

\section{References}

1. Raza HK, Chen H, Chansysouphanthong T, Cui G. The aetiologies of the unilateral oculomotor nerve palsy: a review of the literature. Somatosens Mot Res. 2018;35(3-4):229-39.

2. Fang C, Leavitt JA, Hodge DO, Holmes JM, Mohney BG, Chen JJ. Incidence and Etiologies of Acquired Third Nerve Palsy Using a Population-Based Method. JAMA Ophthalmol. 2017;135(1):23-8.

3. Watanabe K, Hagura R, Akanuma Y, Takasu T, Kajinuma H, Kuzuya N, et al. Characteristics of cranial nerve palsies in diabetic patients. Diabetes Res Clin Pract. 1990;10(1):19-27.

4. Sheikh U, Price CJ, Gutowski NJ. Gliomatosis presenting as a relative pupil-sparing third nerve palsy in a hypertensive diabetic. BMJ Case Rep. 2010; 2010.

5. Venkatesan PE, Gnanashanmugam G, Parimalam N, Pranesh MB. Diabetes plus third nerve palsy not always diabetic third nerve palsy. J Postgrad Med. 2015;61(1):50-2.

6. Mark AS, Blake P, Atlas SW, Ross M, Brown D, Kolsky M. Gd-DTPA enhancement of the cisternal portion of the oculomotor nerve on MR imaging. AJNR Am J Neuroradiol. 1992;13(5):1463-70.

7. Blake PY, Mark AS, Kattah J, Kolsky M. MR of oculomotor nerve palsy. AJNR Am J Neuroradiol. 1995;16(8):1665-72.

8. Ferreira T, Verbist B, van Buchem M, van Osch T, Webb A. Imaging the ocular motor nerves. Eur J Radiol. 2010;74(2):314-22.

9. Bhatti MT, Eisenschenk S, Roper SN, Guy JR. Superior divisional third cranial nerve paresis: clinical and anatomical observations of 2 unique cases. Arch Neurol. 2006;63(5):771-6. 
10. Bhatti MT, Schmalfuss IM, Williams LS, Quisling RG. Peripheral third cranial nerve enhancement in multiple sclerosis. AJNR Am J Neuroradiol. 2003;24(7):1390-5.

11. Anoune M, Abdellaoui M, Benatiya IA, Tahri H. Complete third nerve palsy revealing Tolosa Hunt Syndrome. Pan Afr Med J. 2015;20:137.

12. Hattori M, Takada K, Yamada K, Kamimoto K, Mitake S. A case of Miller Fisher syndrome with gadolinium-enhancing lesions in the cranial nerves and the cauda equina on magnetic resonance imaging. Rinsho Shinkeigaku. 1999;39(10):1054-8.

13. Oomura M, Uchida Y, Sakurai K, Toyoda T, Okita K, Matsukawa N. Miller Fisher Syndrome Mimicking Tolosa-Hunt Syndrome. Intern Med. 2018;57(18):2735-8.

14. O'Hara MA, Anderson RT, Brown D. Magnetic resonance imaging in ophthalmoplegic migraine of children. J AAPOS. 2001;5(5):307-10.

15. Lal V, Sahota P, Singh P, Gupta A, Prabhakar S. Ophthalmoplegia with migraine in adults: is it ophthalmoplegic migraine? Headache. 2009;49(6):838-50.

16. Gelfand AA, Gelfand JM, Prabakhar P, Goadsby PJ. Ophthalmoplegic "migraine" or recurrent ophthalmoplegic cranial neuropathy: new cases and a systematic review. J Child Neurol. 2012;27(6):759-66.

17. Takizawa T, Shibata M, Fujiwara H, Shimizu T, Momoshima S, Suzuki N. Adult-onset recurrent painful ophthalmoplegic neuropathy displaying atypical oculomotor nerve gadolinium-enhancement pattern in the orbit and cavernous sinus. Cephalalgia. 2016;36(2):199-200.

18. Meireles J, Garrett MC, Abreu P. Isolated III cranial nerve palsy: a Hodgkin's lymphoma? BMJ Case Rep. $2014,2014$.

19. Chou KL, Galetta SL, Liu GT, Volpe NJ, Bennett JL, Asbury AK, et al. Acute ocular motor mononeuropathies: prospective study of the roles of neuroimaging and clinical assessment. J Neurol Sci. 2014;219(1-2):35-9.

20. Tamhankar MA, Volpe NJ. Management of acute cranial nerve 3, 4 and 6 palsies: role of neuroimaging. Curr Opin Ophthalmol. 2015;26(6):464-8.

21. Murchison AP, Gilbert ME, Savino PJ. Neuroimaging and acute ocular motor mononeuropathies: a prospective study. Arch Ophthalmol. 2011;129(3):301-5.

22. Edwards JL, Vincent AM, Cheng HT, Feldman EL. Diabetic neuropathy: mechanisms to management. Pharmacol Ther. 2008;120(1):1-34.

23. Pop-Busui R, Ang L, Holmes C, Gallagher K, Feldman EL. Inflammation as a Therapeutic Target for Diabetic Neuropathies. Curr Diab Rep. 2016;16(3):29.

24. Vinik Al, Mehrabyan A. Diabetic neuropathies. Med Clin North Am. 2004;88(4):947-99. xi.

25. Cameron NE, Eaton SE, Cotter MA, Tesfaye S. Vascular factors and metabolic interactions in the pathogenesis of diabetic neuropathy. Diabetologia. 2001;44(11):1973-88.

26. Giannini C, Dyck PJ. Basement membrane reduplication and pericyte degeneration precede development of diabetic polyneuropathy and are associated with its severity. Ann Neurol. 1995;37(4):498-504. 
27. Asbury AK, Aldredge H, Hershberg R, Fisher CM. Oculomotor palsy in diabetes mellitus: a clinicopathological study. Brain. 1970;93(3):555-66.

\section{Figures}
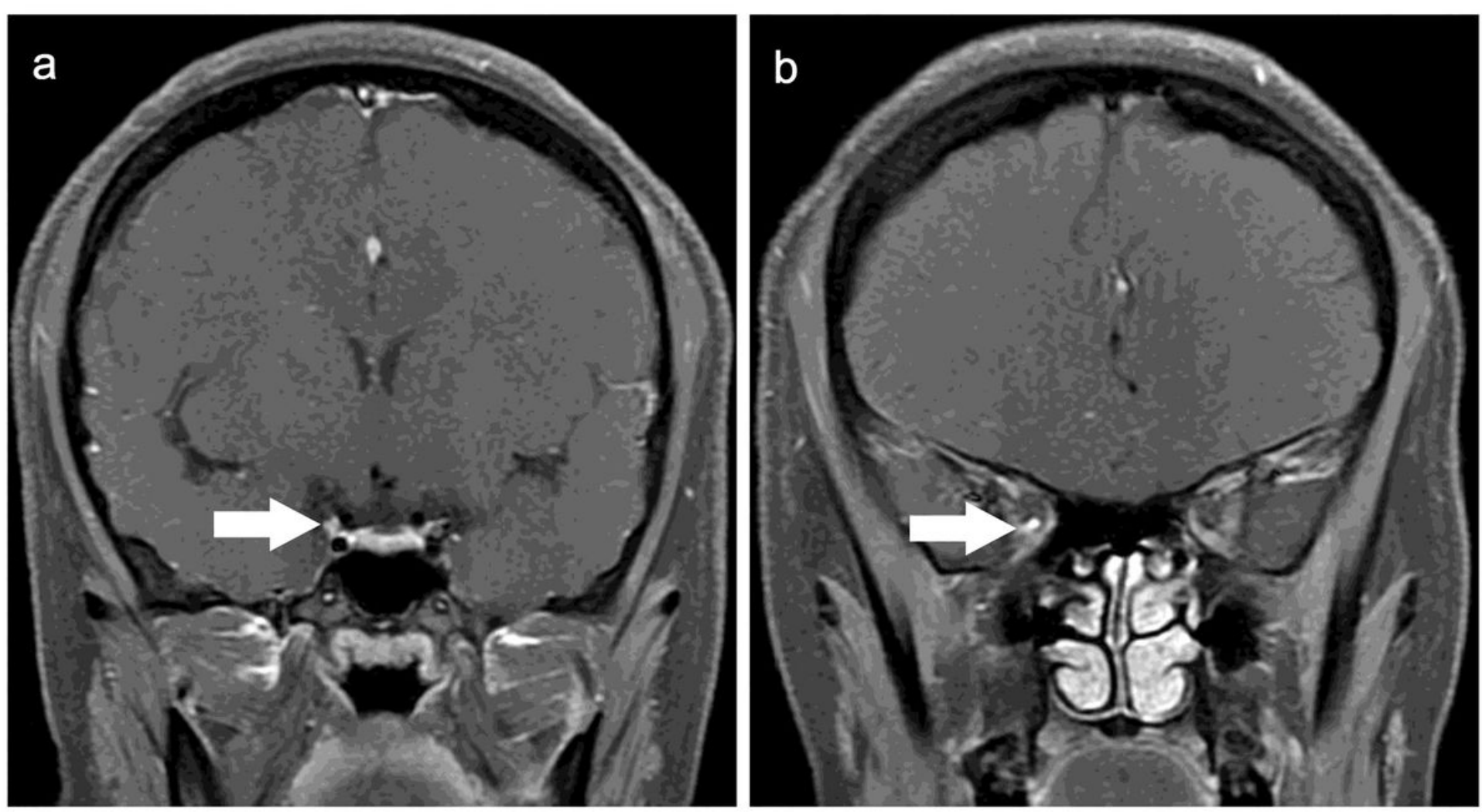

Figure 1

Postgadolinium coronal STIR images on MRI in case 2. (a) Thickening and enhancement of the cavernous segment of the right oculomotor nerve. (b) Thickening and enhancement of the inferior division of the intraorbital segment of the right oculomotor nerve. 


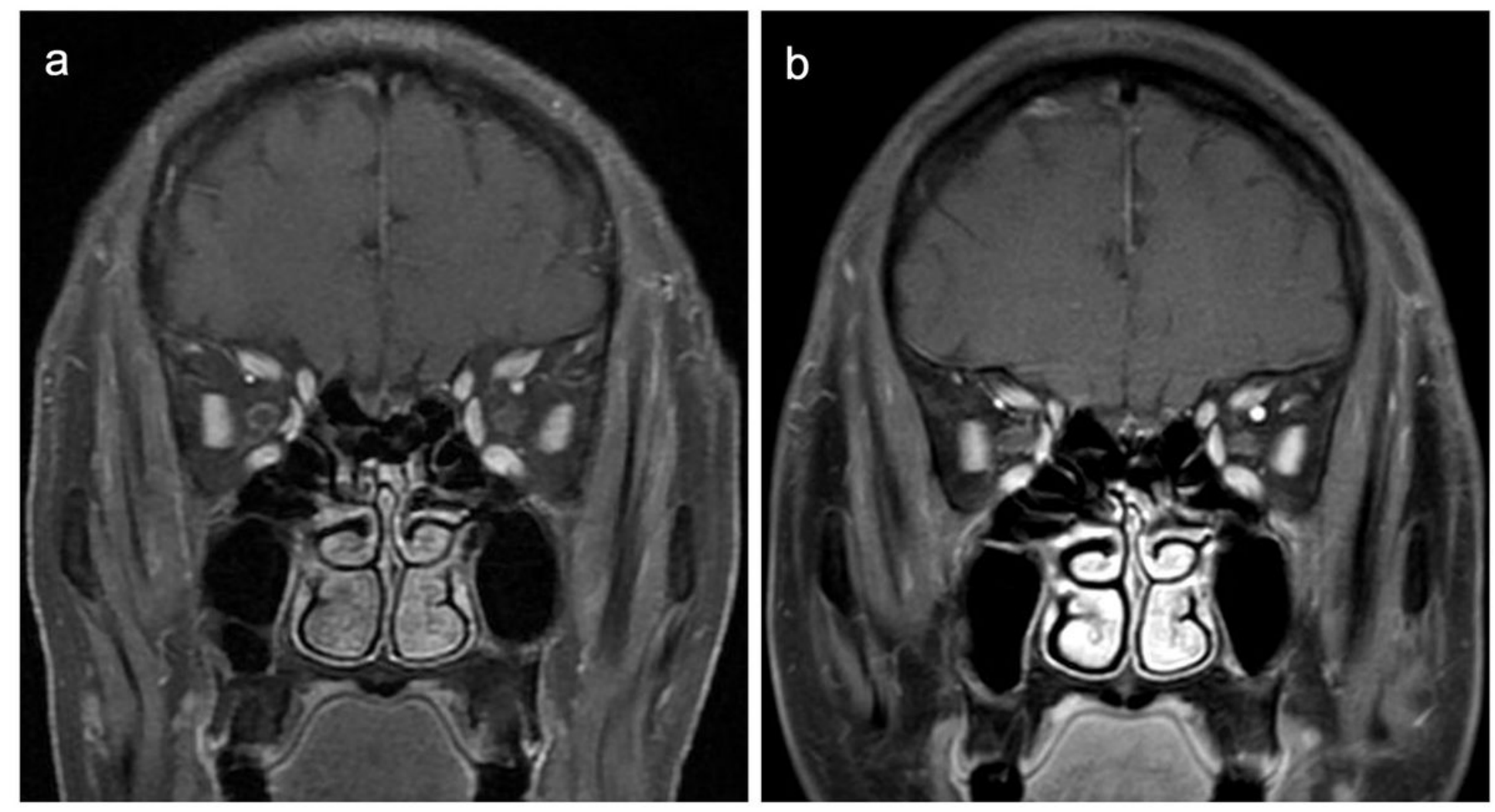

\section{Figure 2}

Postgadolinium coronal STIR images on MRI in case 17. (a) Thinning of the unilateral MR, IR and SMG was shown on images taken 1.5 months after disease onset. (b) Comparative images taken 8 months later displayed that thinning of the EOMs was partly restored. 